\title{
Pengaruh Emotional Marketing dan Spiritual Marketing terhadap Loyalitas Nasabah Tabungan BSM pada Bank Syariah Mandiri KCP Cirebon Siliwangi
}

\author{
Rita Kusumadewi, Intan Lestari \\ Program Studi Perbankan Syariah FSEI IAIN Syekh Nurjati Cirebon \\ E-mail: intan.lestarita@gmail.com; kusumadewi.ryta@gmail.com;
}

\begin{abstract}
Abstrak
Membangun loyalitas adalah bukan pilihan lagi dalam dunia perbankan. Terlebih beberapa tahun terakhir ini muncul satu trend, yaitu kecenderungan nasabah memiliki lebih dari satu rekening tabungan pada Bank yang berbeda. Untuk itu Bank syariah perlu membangun loyalitas nasabah, salah satu cara yang dilakukan adalah dengan pemasaran. Kunci utama dari pemasaran dalam perbankan yaitu membangun hubungan yang kuat secara berkelanjutan dengan nasabah. Beberapa hubungan yang coba dibangun oleh bank syariah dalam pemasaran adalah hubungan secara emosional dan spiritual. Dalam pemasaran lebih dikenal dengan nama emotional marketing dan spiritual marketing. Penelitian ini menggunakan pendekatan kuantitatif. Data yang digunakan dalam penelitian ini adalah data primer dengan teknik pengumpulan data melalui penyebaran kuesioner kepada 100 orang responden nasabah tabungan BSM pada Bank Syariah Mandiri KCP Cirebon Siliwangi. Pengujian menggunakan uji regresi linear berganda dengan SPSS (Stastistical Product and Service Solution) versi 21.0. Hasil penelitian menunjukkan bahwa secara parsial emotional marketing memiliki pengaruh terhadap loyalitas nasabah dengan nilai signifikansi 0,000 dan $t_{\text {hitung }}>t_{\text {tabel }}$ yaitu 6,329 $>1,660$. Kemudian spiritual marketing memiliki pengaruh terhadap loyalitas nasabah dengan nilai signifikansi 0,000 dan $t_{\text {hitung }}>t_{\text {tabel }}$ yaitu 4,919 > 1,660. Dan secara simultan emotional marketing dan spiritual marketing memiliki pengaruh terhadap loyalitas nasabah dengan nilai signifikansi 0,000 dan $F_{\text {hitung }}>F_{\text {tabel }}$ yaitu 38,171>2,36 dengan koefisien determinasi sebesar 44\%, sementara sisanya $56 \%$ dipengaruhi oleh faktor lain.
\end{abstract}

Kata Kunci: Emotional Marketing, Spiritual Marketing, dan Loyalitas Nasabah

\begin{abstract}
Building loyalty is no longer a viable option in the banking world. Especially the last few years comes a trend, namely the tendency of customers to have more than one savings account at different Banks. For that Sharia Bank needs to build customer loyalty, one way to do is with marketing. The main key of marketing in banking is to build a strong relationship in a sustainable manner with customers. Some relationships that the sharia bank is trying to build in marketing are emotionally and spirituall. This research uses quantitative approach. The data used in this study is primary data with data collection techniques through the distribution of questionnaires to 100 respondents of BSM savings customers in Bank Syariah Mandiri KCP Cirebon Siliwangi. The test used multiple linear regression test with SPSS (Stastistical Product and Service Solution) version 21.0. The results showed that partially emotional marketing has an influence on customer loyalty with a significance value of 0.000 and $t$ count $>t$ table is $6.329>1.660$. Then the spiritual marketing has an influence on customer loyalty with a
\end{abstract}


significance value of 0.000 and $t$ count $>t$ table of 4.919> 1.660. And simultaneously emotional marketing and spiritual marketing have influence to customer loyalty with value of significance 0.000 and $F_{\text {_count }}>F_{\text {table }}$ that is 38,171> 2,36 with determination coefficient equal to $44 \%$, while the rest $56 \%$ influenced by other factor.

Keywords: Emotional Marketing, Spiritual Marketing, and Customer Loyalty

\section{Pendahuluan}

Membangun loyalitas adalah bukan pilihan lagi dalam perbankan. Terlebih beberapa tahun terakhir ini muncul salah satu trend yaitu, kecenderungan nasabah untuk memiliki lebih dari satu rekening tabungan, bahkan juga lebih dari satu rekening kartu kredit, yang aktif. Dapat dilihat dari presentasi jumlah kepemilikan rekening tabungan dan kartu kredit pada tahun 2009 sampai dengan $2013 .^{45}$
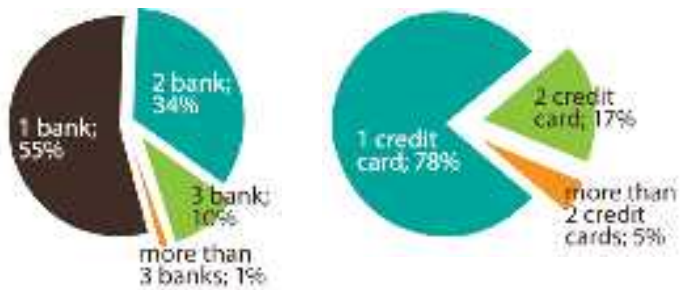

\section{Grafik. Presentasi Jumlah Kepemilikan Rekening Tabungan dan Kartu Kredit Tahun 2009-2013}

Fenomena ini menjadi indikasi bahwa nasabah cenderung tidak loyal dan tidak mau terikat dengan salah satu bank. Umumnya, nasabah memiliki lebih dari satu tabungan karena ingin membedakan rekening simpanan dengan rekening untuk transaksi sehari-hari. Ketersediaan fasilitas transaksi pendukung, seperti ATM dan e-banking, menjadi pertimbangan utama dalam pemilihan rekening untuk transaksi. ${ }^{46}$

45 Hermawan Kartajaya, Taufik, Jacky Mussry, dkk, "Banking Competition in 2013 (in the time of regulatory trantition)," MarkPlus Insight Marketing + Social Research Paper (2013): 6-7.

46 Hermawan Kartajaya, Taufik, Jacky Mussry, dkk,..... 6.
Kenyataan tersebut tentu saja mempersulit bank untuk menjaga loyalitas nasabahnya. Bank harus sangat cermat dalam menyusun program loyalitas agar tidak mudah ditiru dan disaingi oleh bank lain. Oleh karena itu, bank syariah sudah sepatutnya untuk memperbaiki dan memaksimalkan sistem yang belum berjalan dengan sempurna. Salah satunya yaitu dalam hal pemasaran. Kunci utama dari pemasaran dalam perbankan yaitu membangun hubungan yang kuat secara berkelanjutan dengan nasabah. Beberapa hubungan yang coba dibangun oleh bank syariah dalam pemasaran adalah hubungan secara emosional dan spiritual. Dalam pemasaran lebih dikenal dengan nama emotional marketing dan spiritual marketing. Dimana sisi emosional nasabah dilibatkan baik dalam transaksi maupun hubungan berkelanjutan yang coba dibangun oleh bank syariah. Pengalaman yang menyenangkan dari hubungan yang dibangun oleh bank syariah akan diingat oleh nasabah, sehingga diharapkan dapat menjaga loyalitas nasabah. Dari sisi spiritual, bank syariah mencoba memberikan pengalaman yang berbeda. Dimana nasabah akan diberikan pelayanan dalam setiap transaksinya dengan prinsip-prinsip ajaran Islam. Dan dalam spiritual marketing, artinya bisnis dijalankan bertujuan untuk mencari keridhaan Allah swt dan seluruh bentuk transaksinya menjadi ibadah. Sehingga nasabah merasa hubungan yang dijalin dengan bank syariah lebih bermanfaat dibandingkan dengan hubungan bisnis lainnya, karena tidak hanya keuntungan secara dunia yang didapat tetapi juga akhirat. 
Robinette

mengemukakan

bahwa

dan

brand marketing adalah usaha yang dilakukan oleh perusahaan untuk menciptakan hubungan yang berkelanjutan dengan para pelanggan, sehingga mereka merasa berharga dan diperhatikan. ${ }^{47}$ Dampak dari hubungan secara emosional yang dibangun yaitu meningkatkan loyalitas nasabah terhadap bank syariah. Karena ketika seorang nasabah mempunyai ikatan emosional dan diperlakukan secara lebih maka dia akan memperlakukan sebaliknya kepada bank syariah tersebut, yaitu dengan memberikan loyalitasnya.

Sedangkan spiritual marketing menurut Hermawan Kartajaya adalah bentuk pemasaran yang dijiwai nilai-nilai spiritual dalam segala proses dan transaksinya hingga ia sampai pada suatu tingkat ketika semua stakeholders utama dalam bisnis (pelanggan, karyawan dan pemegang saham), pemasok, distributor bahkan pesaing sekalipun memperoleh kebahagiaan. ${ }^{48}$ Dampak dari hubungan secara spiritual yang dibangun yaitu meningkatkan loyalitas nasabah terhadap bank syariah. Karena nasabah akan merasa bahwa bank syariah memberikan nilai-nilai spiritual dalam segala prosesnya, dan itu tidak bisa ditemukan pada bank yang beroperasi secara konvensional.

Dengan menerapkan emotional marketing dan spiritual marketing ini diharapkan nasabah akan memberikan loyalitasnya kepada bank syariah. Karena ketika nasabah sudah loyal kepada bank

47 Rita Kusumadewi, "Pelaksanaan Emotional Marketing melalui The Emotional ES sebagai Pembentuk Loyalitas Pelanggan," Jurnal Al-Amwal Vol. 7 No. 2 (2015): 231.

48Junaidi Abdillah, "Fikih Pemasaran Menguak Pemikiran Hermawan Kartajaya tentang Syariah Marketing",Jurnal Ijtimaiyya (Pengembangan Masyarakat) Vol. 5 No. 1 (Februari 2012): 34. syariah, maka kemungkinan nasabah tersebut puas dengan memakai produk atau jasa pada bank syariah dan kecil kemungkinan nasabah untuk pindah ke bank yang lain.

Penelitian ini menggunakan metode kuantitatif deskriptif, dan menggunakan regresi linier berganda. Populasi berjumlah 7010 nasabah, dengan sampel 100 responden.

Penelitian ini bertujuan untuk mengetahui:

1. Pelaksanaan emotional marketing terhadap loyalitas nasabah tabungan BSM pada bank syariah mandiri KCP Cirebon Siliwangi.

2. Pelaksanaan spiritual marketing terhadap loyalitas nasabah tabungan BSM pada bank syariah mandiri KCP Cirebon Siliwangi.

3. Besar pengaruh emotional marketing terhadap loyalitas nasabah tabungan BSM pada bank syariah mandiri KCP Cirebon Siliwangi.

4. Besar pengaruh spiritual marketing terhadap loyalitas nasabah tabungan BSM pada bank syariah mandiri KCP Cirebon Siliwangi.

5. Besar pengaruh emotional marketing dan spiritual marketing terhadap loyalitas nasabah tabungan BSM pada bank syariah mandiri KCP Cirebon Siliwangi.

\section{Pembahasan}

\section{Teori dan Konsep Emotional Marketing Pengertian Emotional Marketing}

Robinette mengungkapkan definisi emotional marketing adalah teknik yang digunakan perusahaan dalam membangun hubungan berkelanjutan yang membuat pelanggan merasa dihargai. Emotional marketing mengarah ke strategi berbeda bahkan jarang ditiru dan memberikan keunggulan kompetitif yang kuat. $^{49}$

\footnotetext{
${ }^{49}$ Irene Susilo dan Hatane Semuel, "Analisa Pengaruh Emotional Marketing terhadap
} 
Konsep emotional marketing setiap bank berbeda, karena berkaitan dengan emosi seseorang pada suatu waktu akan berbeda dengan waktu yang lainnya. Kemudian, walaupun satu bank dengan bank lainnya menggunakan konsep emotional marketing, tetapi pada saat pelaksanaan baik pelayanan, transaksi, kegiatan, hubungan yang dibangun bank maupun yang lainnya dari setiap bank terhadap nasabahnya akan berbeda.

$\mathrm{T}$ Rytel dalam the concept of marketing mengemukakan bahwa, "emotional marketing, concentrate the importance of emotional link between the company and the consumer affected by the system of the characteristic values and needs of contemporary consumers, which, in turn, forms a new symbol consumption culture. ${ }^{50}$ Emotional marketing berkonsentrasi pada pentingnya hubungan secara emosional antara perusahaan dan a. konsumen yang dipengaruhi oleh sistem dari nilai-nilai, karakterisktik dan kebutuhan konsumen modern, yang mana terus berubah dan berkembang setiap waktu, membentuk budaya konsumsi gaya baru.

Hisham Darwish dalam Think b. Marketing Magazine berpendapat, bahwa Emotional marketing is simply the ability to communicate powerfully through the use of different techniques that evoke emotions. Developers of an emotional marketing strategy can focus on diverse issues to transfer an emotional marketing

Purchase Intention melalui Brand Awareness pada Produk Dove Personal Care di Surabaya," Jurnal Manajemen Pemasaran Vol. 9 No. 1 (April, 2015): 24.

50 Mai Ngoc Khuong and Vu Ngoc Bich Tram, "The Effects of Emotional Marketing on Consumer Product Perception, Brand Awareness and Purchase Decision (A Study in Ho Chi Minh City, Vietnam)," Journal of Economics, Business and Management, Vol. 3, No. 5 (May 2015): 524. message. ${ }^{51}$ Dengan kata lain, emotional marketing adalah pemasaran yang menggunakan kemampuan sebuah perusahaan untuk menyampaikan sebuah produk atau jasa melalui teknik yang berbeda yaitu dengan membangkitkan emosi seorang konsumen. Pengembang dari strategi emotional marketing fokus pada isu-isu yang beragam untuk menyampaikan pesan emotional marketing.

Dapat disimpulkan bahwa emotional marketing adalah suatu konsep pemasaran yang membangun sebuah hubungan emosional secara berkelanjutan antara bank syariah dengan nasabahnya.

Robinette (2001) dalam Irene Susilo dan Hatane Semuel, mengungkapkan bahwa komponen pembentuk emotional marketing meliputi: ${ }^{52}$

Equity: Ekuitas adalah mengenai kepercayaan. Ketika sebuah merek memperoleh kepercayaan dari konsumennya, hal tersebut menjadi fondasi dimana hubungan dengan konsumen semakin berkembang hingga ke loyalitas.

Experience: Berkaitan dengan interaksi pelanggan dengan merek. Sikap pelanggan dipengaruhi oleh kunjungan ke toko atau situs website, kontak karyawan, komunikasi, program loyalitas dan penggunaan produk atau jasa itu sendiri. Hal ini menjadi kesempatan terbaik bagi merek untuk membuat kesan pada pelanggan setelah penjualan.

c. Energy: Produk dan jasa yang dibutuhkan dapat dengan mudah diakses, memudahkan masyarakat, menawarkan kenyamanan dan keefektifan bagi nasabah. Kemudahan

\footnotetext{
${ }^{51}$ Hisham Darwish, "Emotional Marketing." Think Marketing, 10 Mei 2013. https://thinkmarketingmagazine.com/emotio nal-marketing/. Diakses 13 Maret 2013.

52 Irene Susilo dan Hatane Semuel,..... 24.
} 
tersebut menjadi investasi waktu dan usaha pelanggan dalam memperoleh atau menggunakan produk atau jasa.

\section{Teori dan Konsep Spiritual Marketing Pengertian Spiritual Marketing}

Bagi kaum muslim spiritual marketing sangat sarat dengan nilai-nilai syariah dan dalam implementasinya selalu dijiwai oleh nilai-nilai kebenaran yang terpancar dari al-Qur' an dan Sunnah Nabi. Memancarkan cahaya menerangi kegelapan yang pekat dalam dunia bisnis.

Spiritual marketing adalah bentuk pemasaran yang dijiwai nilai-nilai spiritual dalam segala proses dan transaksinya hingga ia sampai pada suatu tingkat ketika semua stakeholders utama dalam bisnis (pelanggan, karyawan dan pemegang saham), pemasok, distributor bahkan pesaing sekalipun memperoleh kebahagiaan. Lebih dari itu, bagi seorang muslim spiritual marketing mengandung nilai-nilai ibadah dan diyakini mendapat ganjaran dan pahala dari Allah SWT di akhirat kelak. ${ }^{53}$

Definisi spiritual marketing sebagaimana yang dimaksudkan oleh Muhammad Syakir Sula, yaitu pemasaran yang bukan berarti hanya melakukan bisnis yang hanya berhubungan dengan ritual ibadah, melainkan spiritual marketing dimaksudkan pelaku bisnis mampu memberikan kebahagiaan kepada setiap orang yang terlibat dalam berbisnis, baik diri kita sendiri, pelanggan, pemasok, distributor, pemilik modal, dan bahkan para pesaing kita. Bahkan disini ditegaskan bahwa kita harus mencintai pelanggan dan sekaligus juga menghargai para pesaing. ${ }^{54}$

\footnotetext{
53 Junaidi Abdillah, "Fikih Pemasaran Menguak Pemikiran Hermawan Kartajaya tentang Syariah Marketing," Jurnal Ijtimaiyya (Pengembangan Masyarakat) Vol. 5 No. 1 (Februari 2012): 34.

${ }^{54}$ Herry Aslam Wahid, "Studi Analisis Pemikiran Muhammad Syakir Sula tentang Model Spiritual Marketing dan Implementasinya dalam Perbankan Syariah (Studi Kasus di Bank Muamalat Indonesia
}

Hifni Alifahmi mengemukakan bahwa spiritual marketing is a sympathetic, touching the conscience, and solid moral message based on the intention of devotion to the divine. ${ }^{55}$ Dengan kata lain, spiritual marketing adalah pemasaran yang simpatik, menyentuh hati nurani, dan pesan moral yang kuat berdasarkan niat pengabdian kepada ilahi.

A.M. Hasan Ali mengemukakan bahwa spiritual marketing is a model of marketing activities based on the spiritual values or Islamic values. ${ }^{56}$ (spiritual marketing adalah model dari kegiatan pemasaran yang berdasarkan pada nilainilai spiritual atau nilai-nilai Islam). Begitu juga Ardhianto mengemukakan bahwa spiritual marketing is this form of marketing is imbued with spiritual values in all processes and transactions until it reached the level when all the major stakeholders in the business of obtaining happiness. ${ }^{57}$ (spiritual marketing adalah bentuk pemasaran yang dijiwai dengan nilai-nilai spiritual dalam semua proses dan transaksi hingga mencapai tingkat ketika semua pelaku utama dalam bisnis untuk memperoleh kebahagiaan). Kemudian diungkapkan juga oleh Basu Swastha Dharmmesta, bahwa spiritual marketing is it is a concept that provides a guarantee for everyone who wants to apply to be a succes the world and the hereafter. $^{58}$ (spiritual marketing adalah konsep pemasaran yang memberikan jaminan bagi semua orang yang ingin terlibat menjadi sukses dunia dan akhirat).

cabang Semarang)." (Skripsi, Fakultas Syariah, IAIN Walisongo Semarang, 2011):21.

55 Anny Nurbasari, "The Impact of Spiritual Marketing on Consumer Behavior in choosing Halal Food (Case study on moslim community in Bandung)," Al Hijaz International Refereed Journal for Islamic \& Arabic Studies Issue 10 (Februari 2015): 277.

${ }^{56}$ Anny Nurbasari,.... 277.

${ }^{57}$ Anny Nurbasari,..... 277.

${ }^{58}$ Anny Nurbasari,..... 277. 
Dari beberapa definisi-definisi di atas, dapat disimpulkan bahwa spiritual marketing adalah suatu konsep pemasaran yang mengacu pada nilai-nilai ajaran Islam yang sesuai dengan al-Qur'an dan Sunnah Nabi pada setiap operasional, transaksi, dan kegiatan bisnisnya. Dimana bisnis yang dijalankan bertujuan untuk mencari keridhaan Allah swt dan seluruh bentuk transaksinya menjadi ibadah. Sehingga hubungan yang dijalin antara nasabah dengan bank syariah bukan hanya hubungan mitra bisnis, tetapi juga hubungan yang bermanfaat baik untuk kehidupan di dunia dan akhirat.

Dalam konsep spiritual marketing Hermawan Kertajaya memberikan tiga karakteristik yang berkaca implementasi berbisnis sesuai dengan ajaran Islam: ${ }^{59}$

a. Teistis (Ketuhanan)

Karakteristik ini adalah karakteristik yang sifatnya religius. Dimana salah satu ciri khas praktik bisnis Rasulullah saw yang tidak dimiliki pebisnis konvensional lainnya adalah sifatnya yang religius. Ini berarti dalam berbisnis Nabi selalu memandang dalam dua perspektif. Pertama, perspektif waktu sekarang, yaitu ketika seseorang masih hidup di dunia. Kedua, perspektif waktu setelah mati, yaitu periode seorang pengusaha meninggal atau kehidupan alam kubur sampai dengan waktu akan dihisab amal perbuatannya. ${ }^{60}$

Pertimbangan adanya pertanggungjawaban yang diminta Tuhan menjadi aspek dominan dalam berbisnis. ${ }^{61}$ Sehingga dalam menjalankan bisnis selalu kembali mengingat bahwa apa yang dilakukan sekarang di dunia adalah semata-mata ibadah.

\footnotetext{
59 Junaidi Abdillah,..... 24.

60 Junaidi Abdillah,..... 24.

61 Junaidi Abdillah,..... 25.
}

Implikasi dari ajaran religiusitas yang ditanamkan Rasulullah saw akan membawa prinsip totalitas dalam hidup manusia. Artinya bahwa apa yang dilakukan manusia tidak lepas dari baik dan buruk yang akan dimintai pertanggungjawaban Tuhan. Karenanya parameter sebuah ibadah tergantung pada hati (niat) seseorang ibadah tidak sekedar ritualistik saja, melainkan makan, minum, tidur, bisnis dan lain-lain akan menjadi ibadah kalau didasarkan niat mencari ridha Allah swt. ${ }^{62}$ Hal ini dijelaskan dalam ayat Al-Qur' an yang artinya:

"Katakanlah, 'Sesungguhnya salatku, ibadahku, hidupku, dan matiku hanyalah untuk Allah, Tuhan semesta alam." (Q.S Al-An'am (6): 162)

b. Humanistis (Kemanusiaan)

Karakteristik ini menunjukkan bahwa spiritual marketing bersifat universal. Walaupun dalam kegiatan, transaksi, dan operasionalnya dijalankan berdasarkan prinsip ajaran Islam, tetapi tidak membeda-bedakan latar belakang mitra bisnis. Pelayanannya tidak membeda-bedakan mitra bisnis baik secara ras, agama dan sebagainya.

c. Etis (Moral dan akhlak)

Karakteristik ini merupakan turunan dari sifat teistis (ketuhanan). Dimana dalam berbisnis dengan menggunakan konsep pemsaran spiritual marketing sangat mengedepankan masalah akhlak (moral dan etika) dalam seluruh aspek kegiatannya.

Karakter benar, amanah, bijaksana, dan komunikatif adalah prinsip-prinsip yang menjadi pilar keberhasilan Rasulullah saw dalam berbisnis. Prinsipprinsip tersebut sebenarnya bersifat universal, kapanpun dan di manapun akan diterima oleh semua manusia. ${ }^{63}$

\footnotetext{
62 Junaidi Abdillah,..... 25.

63 Junaidi Abdillah,..... 26.
} 
Dengan demikian spiritual marketing adalah konsep pemasaran yang mengedepankan nilai-nilai moral dan etika, apapun bentuk agamanya. Karena nilai-nilai moral dan etika adalah nilai yang bersifat universal, yang diajarkan oleh semua agama.

\section{Teori dan Konsep Loyalitas Pengertian Loyalitas}

Salah satu cara yang bisa dilakukan untuk menjaga loyalitas nasabah dalam dunia perbankan adalah dengan mengembangkan konsep pemasarannya masing-masing. Dimana setiap bank mempunyai konsep pemasaran yang berbeda-beda. Tetapi kunci utama dari pemasaran dalam dunia perbankan yaitu membangun hubungan yang kuat secara berkelanjutan dengan nasabah.

Adiwarman Karim menjelaskan bahwa baik atau buruknya perilaku bisnis para pelaku bisnis menentukan suksesgagalnya bisnis yang dijalankan. ${ }^{64}$ Seperti ditegaskan dalam Al-Qur'an:

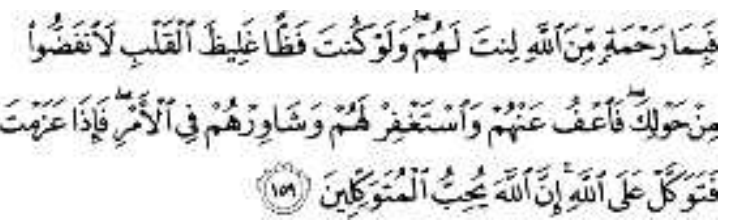

Artinya:

"Maka disebabkan rahmat dari Allah-lah kamu berlaku lemah lembut terhadap mereka. Sekiranya kamu bersikap keras lagi berhati kasar, tentulah mereka menjauhkan diri dari sekelilingmu. Karena itu, maafkanlah mereka; mohonkanlah maupun bagi mereka, dan bermusyawarahlah dengan mereka dalam urusan itu. Kemudian apabila kamu telah membulatkan tekad, maka bertakwallah kepada Allah. Sesungguhnya Allah

64 Winda Yunita Sari, "Analisis Pelaksanaan Pelayanan Transportasi pada Angkutan Trans Metro kota Pekanbaru," (Skripsi, Fakultas Ekonomi dan Ilmu Sosisal, UIN Sultan Syarif Kasim Pekanbaru, 2014): 34. menyukai orang-orang yang bertawakal kepada-Nya." (Q.S Ali Imran (3): 159)

Berdasarkan ayat diatas, jelas bahwa setiap manusia dituntunkan untuk berlaku lemah lembut agar orang lain merasakan kenyamanan bila berada disampingnya. Apalagi dalam pelayanan dalam bank syariah yang mana nasabah banyak pilihan, bila pelaku bisnis tidak mampu memberikan rasa aman dengan kelemahlembutannya maka nasabah akan berpidah ke bank lain. Pelaku bisnis dalam memberikan pelayanan harus menghilangkan jauh-jauh sikap keras hati dan harus memiliki sifat pemaaf kepada nasabah, agar nasabah terhindar dari rasa takut, tidak percaya, dan perasaan adanya bahaya dari pelayanan yang diterima.

Pentingnya memberikan pelayanan yang berkualitas disebabkan pelayanan (service) tidak hanya sebatas mengantarkan atau melayani. Service berarti mengerti, memahami, dan merasakan sehingga penyampaian secara emosionalnya akan mengenai heart share nasabah dan pada akhirnya memperkokoh posisi dalam mind share konsumen. Dengan adanya heart share dan mind share yang tertanam, loyalitas seorang konsumen pada produk atau perusahaan tidak akan diragukan.

Konsep mengenai loyalitas merupakan konsep lama dalam kajian pemasaran dan selalu berkembang dengan berbagai variannya. Wulf, Schroeder dan Lacobucci mendefinisikan loyalitas adalah besarnya konsumsi dan frekuensi pembelian yang dilakukan oleh seorang konsumen terhadap suatu perusahaan. ${ }^{65}$

Kotler mengatakan "the long term succes of the a particular brand is not

65 Rinda Asytuti, Mariska Dewi Anggraini, M. Nasrullah, "Pengaruh Kepercayaan, Kepuasan terhadap Loyalitas dengan Kepemimpinan Pengurus sebagai Variabel Moderating," Jurnal Penelitian Vol. 10 No. 2 (November 2013): 259. 
based on the number who became repeat purchase."66 Dalam hal ini dapat disimpulkan bahwa konsumen yang loyal tidak diukur dari berapa banyak intensitas dia membeli, tapi dari berapa sering melakukan pembelian ulang, termasuk disini merekomendasikan orang lain untuk membeli produk.

Menurut Oliver, customer loyalty is a deeply held commitment rebuy or repatronize a preferred product or service consistently in the future, despite situasuional influences and marketing efforts having the potential to cause switching behavior. ${ }^{67}$ Dengan kata lain, loyalitas pelanggan adalah memegang komitmen pembelian ulang atau berlangganan produk atau melakukan layanan secara konsisten di masa depan, meskipun pengaruh situasional dan upaya pemasaran memiliki potensi untuk menyebabkan beralih.

Dari beberapa definisi-definisi di atas, dapat disimpulkan bahwa loyalitas nasabah adalah besarnya intensitas penggunaan produk dan jasa suatu nasabah kepada bank syariah, disertai dengan merekomendasikannya kepada orang lain, dan tidak terpengaruh untuk menggunakan produk dan jasa dari bank syariah lainnya, walaupun penawaran menarik disediakan oleh bank syariah pesaing dari yang digunakan nasabah tersebut.

66 Ida Farida, "Pengaruh Penerapan Layanan Marketing Syariah dan Kepuasan Pelanggan terhadap Loyalitas Pelanggan (Rumah Makan Wong Solo Cabang Tebet)," (Skripsi, Fakultas Syariah dan Hukum, UIN Syarif Hidayatullah Jakarta, 2011) $: 62$.

67 Hafiz Eka Prawira Siregar, "Pengaruh Penerapan Strategi Pemasaran Rasional, Emosional, dan Spiritual terhadap Kepuasan dan Loyalitas Nasabah PT. Bank Mandiri Syariah Cabang Medan Ahmad Yani." (Skripsi, Fakultas Ekonomi dan Bisnis, Universitas Sumatera Utara, 2015): 11.
Menurut Griffin, loyalitas pelanggan dapat diukur dengan empat indikator, yaitu dengan melakukan pembelian berulang secara teratur, melakukan pembelian antarlini produk dan jasa, merekomendasikan produk atau jasa kepada orang lain, dan menunjukkan kekebalan terhadap tarikan pesaing. ${ }^{68}$

Menurut Kotler dalam Sulfiyah loyalitas dapat diukur dengan 3 (tiga) indikator, yaitu: ${ }^{69}$

1) Repeat, yaitu nasabah melakukan pembelian barang atau jasa yang disediakan oleh penyedia jasa yang bersangkutan secara berulang.

2) Retention, yaitu ia tidak terpengaruh jasa yang ditawarkan oleh pihak lain.

3) Refferral, yaitu apabila jasa yang diterima memuaskan, maka nasabah akan memberitahukan kepada pihak lain dan sebaliknya apabila ada ketidakpuasan atas pelayanan yang diterima ia tidak akan bicara kepada pihak lain justru akan memberitahukan pelayanan yang kurang memuaskan tersebut pada pihak penyedia jasa.

\section{Penelitian Terdahulu}

Sebelum penelitian ini ada beberapa penelitian yang mencoba untuk meneliti pengaruh emotional marketing, maupun spiritual marketing terhadap loyalitas nasabah pada suatu bank maupun pelanggan pada suatu perusahaan. Penelitian tersebut antara lain:

\footnotetext{
68 Dessy Wulansari dan Yessy Artanti, "Pengaruh Pemasaran berdasarkan Pengalaman, Pemasaran Emosional terhadap Loyalitas Pelanggan," Jurnal Ilmu Manajemen Vol. 2 No. 4 (Oktober 2014): 1771.

69 Sulfiyah, "Pengaruh Kualitas Customer Service terhadap Loyalitas Nasabah Pada Bank Muamalat Indonesia Cabang Cirebon." (Skripsi, Fakultas Syariah, IAIN Syekh Nurjati Cirebon, 2012): 12-13.
} 
Tabel. Penelitian Terdahulu

\begin{tabular}{|c|c|c|c|}
\hline No & $\begin{array}{c}\text { Penulis/ } \\
\text { Tahun }\end{array}$ & $\begin{array}{c}\text { Judul } \\
\text { Penelitian } \\
\end{array}$ & Hasil Penelitian \\
\hline 1. & $\begin{array}{c}\text { Dessy } \\
\text { Wulansari } \\
\text { dan Yessy } \\
\text { Artanti } \\
(2014)\end{array}$ & $\begin{array}{l}\text { Pengaruh } \\
\text { pemasaran } \\
\text { berdasarkan } \\
\text { pengalaman, } \\
\text { pemasaran } \\
\text { emosional } \\
\text { terhadap } \\
\text { loyalitas } \\
\text { pelanggan }\end{array}$ & $\begin{array}{c}\text { Hasil penelitian } \\
\text { menunjukkan } \\
\text { bahwa } \\
\text { pemasaran } \\
\text { berdasarkan } \\
\text { pengalaman, } \\
\text { pemasaran } \\
\text { emosional } \\
\text { berpengaruh } \\
\text { secara signifikan } \\
\text { terhadap } \\
\text { loyalitas } \\
\text { pelanggan pada } \\
\text { dua kelompok. } \\
\text { Kelompok } \\
\text { experimen } \\
\text { menunjukkan } \\
\text { tingkat loyalitas } \\
\text { pelanggan lebih } \\
\text { besar dari } \\
\text { kelompok } \\
\text { kontrol. }\end{array}$ \\
\hline 2. & $\begin{array}{c}\text { Erma } \\
\text { Sulistyo Rini } \\
(2016)\end{array}$ & $\begin{array}{l}\text { Pengaruh } \\
\text { experential } \\
\text { marketing dan } \\
\text { emotional } \\
\text { marketing } \\
\text { terhadap } \\
\text { loyalitas } \\
\text { pelanggan di } \\
\text { STIKOM Bali }\end{array}$ & $\begin{array}{c}\text { Hasil penelitian } \\
\text { menunjukkan } \\
\text { bahwa } \\
\text { emotional } \\
\text { marketing } \\
\text { memiliki } \\
\text { pengaruh paling } \\
\text { signifikan } \\
\text { terhadap } \\
\text { loyalitas } \\
\text { pelanggan di } \\
\text { STIKOM Bali. }{ }^{27}\end{array}$ \\
\hline 3. & $\begin{array}{c}\text { Osin Tauli } \\
\text { dan Marhadi } \\
\text { (2012) }\end{array}$ & $\begin{array}{c}\text { Pengaruh } \\
\text { emotional } \\
\text { marketing dan } \\
\text { experiental } \\
\text { marketing } \\
\text { terhadap } \\
\text { customer loyalty } \\
\text { pondok khas } \\
\text { melayu di } \\
\text { Pekanbaru }\end{array}$ & $\begin{array}{l}\text { Hasil penelitian } \\
\text { ini menunjukkan } \\
\text { bahwa hanya } \\
\text { sense (faktor } \\
\text { experiental } \\
\text { marketing) yang } \\
\text { memiliki } \\
\text { pengaruh } \\
\text { terhadap } \\
\text { loyalitas } \\
\text { pelanggan } \\
\text { secara } \\
\text { signifikan. } \\
\text { s. }\end{array}$ \\
\hline 4. & $\begin{array}{c}\text { Rita } \\
\text { Kusumadewi } \\
(2015)\end{array}$ & $\begin{array}{l}\text { Pelaksanaan } \\
\text { emotional } \\
\text { marketing } \\
\text { melalui the } \\
\text { emotional ES } \\
\text { sebagai } \\
\text { pembentuk } \\
\end{array}$ & $\begin{array}{l}\text { Hasil penelitian } \\
\text { menunjukkan } \\
\text { bahwa dari } \\
\text { ketiga faktor } E \\
\text { (Equity, } \\
\text { Experience dan } \\
\text { Energy) tersebut }\end{array}$ \\
\hline
\end{tabular}

${ }^{26}$ Dessy Wulansari dan Yessy Artanti, "Pengaruh Pemasaran berdasarkan Pengalaman, Pemasaran Emosional terhadap Loyalitas Pelanggan," Jurnal Ilmu Manajemen Vol. 2 No. 4 (Oktober 2014).

27 Erma Sulistyo Rini, "Pengaruh experential marketing dan emotional marketing terhadap loyalitas pelanggan di STIKOM Bali," Jurnal Ilmiah SISFOTENIKA Vol. 6 No. 2 (Juli 2016).

28 Osin Tauli dan Marhadi, "Pengaruh Emotion Marketing dan Experiental Marketing terhadap Customer Loyalty Pondok Khas Melayu di Pekanbaru," Jurnal Ekonomi Vol. 20 No. 4 (Desember 2012).

\begin{tabular}{|c|c|c|c|}
\hline & & $\begin{array}{l}\text { loyalitas } \\
\text { pelanggan }\end{array}$ & $\begin{array}{c}\text { yang paling } \\
\text { mempengaruhi } \\
\text { seorang menjadi } \\
\text { pelanggan agar } \\
\text { menjadi } \\
\text { pelanggan loyal } \\
\text { adalah } \\
\text { Experience. }^{29}\end{array}$ \\
\hline 5. & $\begin{array}{c}\text { Tias A. } \\
\text { Indarwati } \\
\text { dan Monika } \\
\text { Tiarawati } \\
\text { (2015) }\end{array}$ & $\begin{array}{c}\text { Strategi } \\
\text { pemasaran } \\
\text { melalui } \\
\text { experience dan } \\
\text { emotional } \\
\text { marketing } \\
\text { terhadap } \\
\text { kepuasan dan } \\
\text { loyalitas } \\
\text { pelanggan di } \\
\text { J.Co donuts dan } \\
\text { caffee Surabaya }\end{array}$ & $\begin{array}{l}\text { Hasil penelitian } \\
\text { menunjukkan } \\
\text { bahwa, baik } \\
\text { experience } \\
\text { maupun } \\
\text { emotional } \\
\text { marketing } \\
\text { berpengaruh } \\
\text { positif terhadap } \\
\text { kepuasan dan } \\
\text { loyalitas } \\
\text { pelanggan di } \\
\text { J.Co donuts dan } \\
\text { caffee } \\
\text { Surabaya. }\end{array}$ \\
\hline 6. & $\begin{array}{l}\text { Abdullah } \\
\text { Barori } \\
(2014)\end{array}$ & $\begin{array}{l}\text { Pengaruh } \\
\text { emotional } \\
\text { marketing, } \\
\text { experiental } \\
\text { marketing, dan } \\
\text { kepuasan } \\
\text { pelanggan } \\
\text { terhadap } \\
\text { loyalitas } \\
\text { pelanggan G- } \\
\text { Sports centre } \\
\text { Padang }\end{array}$ & $\begin{array}{c}\text { Hasil penelitian } \\
\text { menunjukkan } \\
\text { emotional } \\
\text { marketing tidak } \\
\text { berpengaruh } \\
\text { terhadap } \\
\text { loyalitas } \\
\text { pelanggan } \\
\text { sementara } \\
\text { experiential } \\
\text { marketing dan } \\
\text { kepuasan } \\
\text { pelanggan } \\
\text { berpengaruh } \\
\text { signifikan dan } \\
\text { positif terhadap } \\
\text { loyalitas } \\
\text { pelanggan G- } \\
\text { Sport Centre } \\
\text { Padang. }{ }^{31}\end{array}$ \\
\hline 7. & $\begin{array}{c}\text { Riyanti Nur } \\
\text { Shobah } \\
(2012)\end{array}$ & $\begin{array}{l}\text { Analisis faktor- } \\
\text { faktor yang } \\
\text { mempengaruhi } \\
\text { loyalitas } \\
\text { nasabah }\end{array}$ & $\begin{array}{c}\text { Hasil penelitian } \\
\text { menunjukkan } \\
\text { bahwa nilai } \\
\text { pelanggan, } \\
\text { kualitas } \\
\text { pelayanan, dan } \\
\text { kedekatan } \\
\text { emosional } \\
\text { berpengaruh } \\
\text { positif terhadap }\end{array}$ \\
\hline
\end{tabular}

29 Rita Kusumadewi, "Pelaksanaan Emotional Marketing melalui The Emotional ES sebagai Pembentuk Loyalitas Pelanggan," Jurnal Al-Amwal Vol. 7 No. 2 (2015).

${ }^{30}$ Tias A. Indarwati dan Monika Tiarawati, "Strategi pemasaran melalui experience dan emotional marketing terhadap kepuasan dan loyalitas pelanggan di J.Co donuts dan caffee Surabaya," Jurnal Riset Ekonomi dan Manajemen Vol.15 No.1 (Juni 2015).

${ }^{31}$ Abdullah Barori, "Pengaruh Emotional Marketing, Experiental Marketing, dan Kepuasan Pelanggan terhadap Loyalitas Pelanggan G-Sports Centre Padang." (Skripsi, Fakultas Ekonomi, Universitas Andalas Padang, 2014). 


\begin{tabular}{|c|c|c|c|}
\hline & & & $\begin{array}{l}\text { loyalitas } \\
\text { nasabah. }^{32}\end{array}$ \\
\hline 8. & $\begin{array}{l}\text { Nur Ayu } \\
\text { Rizqia } \\
(2013)\end{array}$ & $\begin{array}{l}\text { Pengaruh faktor } \\
\text { spiritual } \\
\text { marketing } \\
\text { terhadap } \\
\text { loyalitas } \\
\text { nasabah (studi } \\
\text { BMI cabang } \\
\text { pembantu Pati) }\end{array}$ & $\begin{array}{c}\text { Hasil dari } \\
\text { penelitian ini } \\
\text { menunjukkan } \\
\text { bahwa terdapat } \\
\text { pengaruh yang } \\
\text { signifikan antara } \\
\text { faktor spiritual } \\
\text { marketing teistis } \\
\text { (rabbaniyyah), } \\
\text { humanistis } \\
\text { (insaniyyah), } \\
\text { realistis } \\
\text { (alwaqi'iyyah) } \\
\text { dan etis } \\
\text { (akhlaqiyyah) } \\
\text { terhadap } \\
\text { loyalitas } \\
\text { nasabah pada } \\
\text { Bank Muamalat } \\
\text { Indonesia } \\
\text { Cabang } \\
\text { Pembantu Pati. }\end{array}$ \\
\hline 9. & $\begin{array}{c}\text { Herry Aslam } \\
\text { Wahid } \\
(2011)\end{array}$ & $\begin{array}{c}\text { Studi analisis } \\
\text { pemikiran } \\
\text { Muhammad } \\
\text { Syakir Sula } \\
\text { tentang model } \\
\text { spiritual } \\
\text { marketing dan } \\
\text { implementasinya } \\
\text { dalam } \\
\text { perbankan } \\
\text { syariah (studi } \\
\text { kasus di Bank } \\
\text { Muamalat } \\
\text { Indonesia } \\
\text { cabang } \\
\text { Semarang) }\end{array}$ & $\begin{array}{c}\text { Hasil penelitian } \\
\text { menunjukkan } \\
\text { bahwa terdapat } \\
\text { persamaan } \\
\text { dalam konsep } \\
\text { dan praktek } \\
\text { spiritual } \\
\text { marketing antara } \\
\text { pemikiran } \\
\text { Muhammad } \\
\text { Syakir Sula } \\
\text { dengan praktek } \\
\text { operasional } \\
\text { Bank Mualamat } \\
\text { Indonesia } \\
\text { Cabang } \\
\text { Semarang, baik } \\
\text { itu mengenai } \\
\text { pemahaman } \\
\text { mengenai } \\
\text { spiritual } \\
\text { marketing, } \\
\text { praktek etika } \\
\text { bisnis syariah, } \\
\text { dan pengelolaan } \\
\text { bisnis dengan } \\
\text { mengedepankan } \\
\text { aspek keadilan. } \\
\text {.4 }\end{array}$ \\
\hline 10. & $\begin{array}{l}\text { Ida Farida } \\
\text { (2011) }\end{array}$ & $\begin{array}{l}\text { Pengaruh } \\
\text { penerapan } \\
\text { layanan } \\
\text { marketing }\end{array}$ & $\begin{array}{c}\text { Hasil penelitian } \\
\text { menyatakan } \\
\text { bahwa terdapat } \\
\text { hubungan searah }\end{array}$ \\
\hline
\end{tabular}

${ }^{32}$ Riyanti Nur Shobah, "Analisis Faktor-faktor yang Mempengaruhi Loyalitas Nasabah.” (Skripsi, Fakultas Syariah, IAIN Syekh Nurjati Cirebon, 2012).

${ }^{33}$ Nur Ayu Rizqia, "Pengaruh Faktor Spiritual Marketing terhadap Loyalitas Nasabah (Studi pada Bank Muamalat Indonesia)." (Skripsi, Fakultas Syariah dan Ekonomi Islam, IAIN Walisongo Semarang, 2013).

${ }^{34}$ Herry Aslam Wahid, "Studi Analisis Pemikiran Muhammad Syakir Sula tentang Model Spiritual Marketing dan Implementasinya dalam Perbankan Syariah (Studi Kasus di Bank Muamalat Indonesia cabang Semarang)." (Skripsi, Fakultas Syariah, IAIN Walisongo Semarang, 2011).

\begin{tabular}{|c|c|c|c|}
\hline & & $\begin{array}{l}\text { syariah dan } \\
\text { kepuasan } \\
\text { pelanggan } \\
\text { terhadap } \\
\text { loyalitas } \\
\text { pelanggan } \\
\text { (rumah makan } \\
\text { wong solo } \\
\text { cabang tebet) }\end{array}$ & $\begin{array}{c}\text { dan signifikan } \\
\text { antara kualitas } \\
\text { layanan } \\
\text { terhadap } \\
\text { kepuasan } \\
\text { pelanggan, } \\
\text { sementara } \\
\text { kepuasan } \\
\text { pelanggan } \\
\text { terhadap } \\
\text { loyalitas } \\
\text { pelanggan } \\
\text { pengaruhnya } \\
\text { sangat kuat. }\end{array}$ \\
\hline 11. & $\begin{array}{c}\text { Endang } \\
\text { Sulistya Rini } \\
\text { dan Yeni } \\
\text { Absah } \\
(2015)\end{array}$ & $\begin{array}{c}\text { Analisis } \\
\text { penciptaan } \\
\text { loyalitas melalui } \\
\text { pengaruh } \\
\text { penerapan } \\
\text { strategi } \\
\text { pemasaran } \\
\text { rasional, } \\
\text { emosional, dan } \\
\text { spiritual } \\
\text { terhadap } \\
\text { kepuasan } \\
\text { nasabah PT. } \\
\text { Bank Sumut } \\
\text { Syariah cabang } \\
\text { utama Medan }\end{array}$ & $\begin{array}{c}\text { Hasil } \\
\text { penelitian } \\
\text { menunjukkan } \\
\text { bahwa } \\
\text { strategi } \\
\text { pemasaran } \\
\text { emosional } \\
\text { dan spiritual } \\
\text { berpengaruh } \\
\text { langsung } \\
\text { secara positif } \\
\text { dan } \\
\text { signifikan } \\
\text { terhadap } \\
\text { kepuasan } \\
\text { nasabah, } \\
\text { sedangkan } \\
\text { strategi } \\
\text { pemasaran } \\
\text { rasional } \\
\text { berpengaruh } \\
\text { tidak } \\
\text { signifikan } \\
\text { terhadap } \\
\text { kepuasan } \\
\text { nasabah. } \\
\text { Kepuasan } \\
\text { nasabah } \\
\text { berpengaruh } \\
\text { positif dan } \\
\text { signifikan } \\
\text { terhadap } \\
\text { loyalitas } \\
\text { nasabah } \\
\text { Bank Sumut } \\
\text { Syariah } \\
\text { Cabang } \\
\text { Utama } \\
\text { Medan.36 }\end{array}$ \\
\hline 12. & $\begin{array}{c}\text { Langgeng } \\
\text { Setyono, } \\
\text { Andriani } \\
\text { Kusumawati, } \\
\text { dan M. } \\
\text { Kholid }\end{array}$ & $\begin{array}{c}\text { Pengaruh } \\
\text { spiritual } \\
\text { marketing dan } \\
\text { citra perusahaan } \\
\text { terhadap } \\
\text { kepuasan dan }\end{array}$ & $\begin{array}{c}\text { Hasil penelitian } \\
\text { menunjukkan } \\
\text { bahwa spiritual } \\
\text { marketing } \\
\text { berpengaruh } \\
\text { signifikan }\end{array}$ \\
\hline
\end{tabular}

35 Ida Farida, "Pengaruh Penerapan Layanan Marketing Syariah dan Kepuasan Pelanggan terhadap Loyalitas Pelanggan (Rumah Makan Wong Solo Cabang Tebet)," (Skripsi, Fakultas Syariah dan Hukum, UIN Syarif Hidayatullah Jakarta, 2011).

${ }^{36}$ Endang Sulistya Rini dan Yeni Absah, "Analisis Penciptaan Loyalitas melalui Pengaruh Penerapan Strategi Pemasaran Rasional, Emosional, dan Spiritual terhadap Kepuasan Nasabah PT. Bank Sumut Syariah cabang utaman Medan," Jurnal Studi Manajemen dan Bisnis Vol. 2 No. 1 (2015). 


\begin{tabular}{|c|c|c|}
\hline $\begin{array}{l}\text { Mawardi } \\
\text { (2015) }\end{array}$ & $\begin{array}{c}\text { loyalitas } \\
\text { nasabah (studi } \\
\text { pada Bank } \\
\text { Muamalat } \\
\text { Indonesia } \\
\text { Kantor Cabang } \\
\text { Malang) }\end{array}$ & $\begin{array}{c}\text { terhadap } \\
\text { kepuasan } \\
\text { nasabah dan } \\
\text { loyalitas } \\
\text { nasabah, citra } \\
\text { perusahaan } \\
\text { berpengaruh } \\
\text { signifikan } \\
\text { terhadap } \\
\text { kepuasan } \\
\text { nasabah dan } \\
\text { loyalitas } \\
\text { nasabah, dan } \\
\text { kepuasaan } \\
\text { nasabah } \\
\text { berpengaruh } \\
\text { signifikan } \\
\text { terhadap } \\
\text { loyalitas } \\
\text { nasabah. }{ }^{37}\end{array}$ \\
\hline
\end{tabular}

\section{Hipotesis}

Berdasarkan telaah pustaka dan penelitian terdahulu diatas, hipotesis penelitian yang akan diuji dalam penelitian adalah:

1. Terdapat pengaruh positif signifikan emotional marketing terhadap loyalitas nasabah tabungan BSM pada bank syariah mandiri KCP Siliwangi.

2. Terdapat pengaruh positif signifikan spiritual marketing terhadap loyalitas nasabah tabungan BSM pada bank syariah mandiri KCP Siliwangi.

\section{Metode Penelitian}

Populasi dan sampel dalam penelitian ini adalah nasabah Bank Syariah Mandiri KCP Cirebon Siliwangi. Pengambilan sampel sebanyak 100 responden dengan rumus dari Slovin Teknik sampling yang digunakan dalam penelitian ini adalah purposive sampling. Kriteria sampel dalam penelitian ini adalah nasabah aktif yang telah menjadi nasabah tabungan BSM pada Bank Syariah Mandiri KCP Cirebon Siliwangi dalam jangka waktu minimal 3 bulan. Dimana yang dikatakan nasabah aktif disini merupakan nasabah yang setiap bulannya melakukan

\footnotetext{
${ }^{37}$ Langgeng Setyono, Andriani Kusumawati, dan M. Kholid Mawardi, "Pengaruh spiritual marketing dan citra perusahaan terhadap kepuasan dan loyalitas nasabah (studi pada Bank Muamalat Indonesia Kantor Cabang Malang)," Jurnal Administrasi Bisnis Vol. 27 No. 1 (Oktober 2015).
}

transaksi. Adapun tenik analisis yang digunakan adalah regresi linear berganda.

\section{Hasil Penelitian dan Pembahasan}

Berdasarkan hasil olah data yang dilakukan peneliti pada 100 orang responden tentang karakteristik jenis kelamin responden dDiketahui bahwa jenis kelamin yang terbanyak menabung saat dilakukan penelitian pada bulan April adalah laki-laki yaitu sebanyak 61 orang, kemudian diikuti dengan jenis kelamin perempuan sebanyak 39 orang. Hal tersebut menunjukkan bahwa perempuan tidak mendominasi responden dalam penelitian ini. Padahal jika dilihat dari jenis kelamin yang mengambil keputusan lebih mengedepankan sisi emosional adalah perempuan dibandingkan laki-laki. Tetapi hal tersebut tidak menjadi kendala dalam penelitian ini karena ada 39 orang perempuan yang menjadi responden.

Karakteristik berdasarkan pekerjaan responden diketahui bahwa responden yang terbanyak mempunyai pekerjaan sebagai pegawai swasta yaitu 45 orang dan paling sedikit adalah wiraswasta dan mahasiswa dengan jumlah masing-masing 3 orang. Hal ini menunjukkan bahwa sebagian besar nasabah yang menggunakan tabungan BSM di Bank Syariah Mandiri KCP Cirebon Siliwangi bekerja sebagai pegawai swasta. Kenyataan tersebut didukung sebagaimana diketahui bahwa pendapatan yang diperoleh oleh Pegawai Negeri Sipil dan pegawai BUMN biasanya melalui Bank Rakyat Indonesia. Sehingga tidak menutup kemungkinan apabila PNS, Pegawai BUMN, dan pekerjaan lainnya menabung pada Bankbank lain yang menyalurkan pendapatan mereka.

Berdasarkan hasil olah data yang dilakukan peneliti pada 100 orang responden tentang karakteristik berdasarkan pendapatan responden diketahui bahwa responden yang terbanyak mempunyai pendapatan sebesar Rp. 5.000.001 - Rp. 10.000.000 sebanyak 68 orang, dan paling sedikit 8 orang mempunyai pendapatan sebesar Rp.10.000.001 Rp.15.000.000. Hal ini sesuai dengan karakterisktik responden berdasarkan 
perkerjaan yang terbanyak adalah pegawai swasta, dan pendapatan responden terbanyak adalah sebesar Rp. 5.000.001 - Rp. 10.000.000, karena sebagaimana kita ketahui apabila Pegawai Negeri Sipil gaji pokok rata-ratanya $<$ Rp. 5.000.001.

Karakteristik berdasarkan pendidikan terakhir responden diketahui bahwa responden yang terbanyak adalah lulusan S1 yaitu sebanyak 52 orang, dan paling sedikit adalah lulusan SMP dan Diploma dengan jumlah masing-masing 2 orang. Hal ini sesuai dengan karakterisktik responden berdasarkan perkerjaan yang terbanyak adalah pegawai swasta, sehinga menunjukkan bahwa nasabah tabungan BSM yang mempunyai pekerjaan sebagai pegawai swasta mempunyai tingkat pendidikan terakhir S1. Tetapi tidak menutup kemungkinan juga apabila pegawai swasta mempunyai pendidikan dibawah S1, karena tidak ada persyaratan khusus untuk pegawai swasta.

Sedangkan karakteristik berdasarkan lama menabung responden diketahui bahwa responden terbanyak telah menabung lebih dari 4 tahun sebanyak 54 orang, dan paling sedikit telah menabung 3 sampai dengan 4 tahun. Hal ini menunjukkan bahwa karakteristik responden yang sering melakukan transaksi paling banyak di Bank adalah mereka yang telah menabung $>4$ tahun di BSM. Sedangkan yang lainnya bisa jadi sering melakukan transaksinya dengan e-Banking atau ATM, sehingga tidak bertemu dengan peneliti. Tetapi dengan responden yang melakukan transaksi ke Bank menunjukkan bahwa mereka sering melakukan transaksi di Bank Syariah Mandiri KCP Cirebon Siliwangi. Dan dengan banyaknya yang bertransaksi di Bank adalah nasabah yang telah menabung $>4$ tahun dibandingkan dengan nasabah yang menabung $<4$ tahun, peneliti menyimpulkan bahwa loyalitas dari nasabah tabungan BSM untuk melakukan transaksi secara langsung di BSM KCP Cirebon Siliwagi bagus.

\section{Uji hipotesis}

Sebelum dilakukan uji hipotesis, terlebih dahulu dilakukan uji model dengan menggunakan uji F.

\section{Tabel. Hasil Uji F}

\begin{tabular}{|c|c|c|c|c|c|c|}
\hline \multicolumn{2}{|c|}{ Model } & $\begin{array}{c}\text { Sum of } \\
\text { Squares }\end{array}$ & Df & $\begin{array}{l}\text { Mean } \\
\text { Square }\end{array}$ & $\mathrm{F}$ & Sig. \\
\hline \multirow{3}{*}{1} & Regression & 239,034 & 2 & 119,517 & 38,171 &, $000^{\circ}$ \\
\hline & Residual & 303,716 & 97 & 3,131 & & \\
\hline & Total & 542,750 & 99 & & & \\
\hline
\end{tabular}

(Sumber: Data Primer, Diolah Tahun 2017)

Berdasarkan hasil pengujian hipotesis dengan uji $f$ (simultan) dapat dihasilkan analisis bahwa nilai signifikansi untuk pengaruh $\mathrm{X}_{1}$ dan $\mathrm{X}_{2}$ secara simultan (bersama-sama) terhadap $\mathrm{Y}$ adalah sebesar $0,000<0,05$ dan nilai $\mathrm{F}$ hitung 38,171 > F tabel 2,36, sehingga dapat disimpulkan bahwa terdapat pengaruh $\mathrm{X}_{1}$ dan $\mathrm{X}_{2}$ secara simultan terhadap Y. Artinya bahwa model yang dibangun yaitu spiritual marketing dan emotional marketing berpengaruh terhadap loyalitas nasabah. Adapun besar pengaruh kedua variable bebas tersebut bias dilihat dari table berikut:

\section{Tabel. Hasil Uji Koefisien Determinasi}

\begin{tabular}{|l|r|r|r|r|}
\hline Model & \multicolumn{1}{|c|}{ M } & R Square & \multicolumn{1}{c|}{$\begin{array}{c}\text { Adjusted R } \\
\text { Square }\end{array}$} & $\begin{array}{c}\text { Std. Error of the } \\
\text { Estimate }\end{array}$ \\
\hline 1 &, $664^{\mathrm{a}}$ &, 440 &, 429 & 1,76949 \\
\hline a. Predictors: (Constant), Spiritual Marketing, Emotional Marketing
\end{tabular}

Sumber: Data Primer, Diolah Tahun 2017

Berdasarkan tabel di atas diketahui nilai $\mathrm{R}$ Square sebesar 0,440, hal ini mengandung arti bahwa pengaruh variabel $\mathrm{X} 1$ dan $\mathrm{X} 2$ secara simultan (bersama-sama) terhadap variabel $\mathrm{Y}$ adalah sebesar $44,0 \%$. Sisanya $56,0 \%$ dipengaruhi oleh faktor lain yang tidak diteliti dalam penelitian ini.

Adapun hasil uji t (parsial) yang diperoleh dalam penelatian ini adalah sebagai berikut:

Tabel. Hasil Uji t Coefficients $^{\mathrm{a}}$

\begin{tabular}{|c|c|c|c|c|c|c|}
\hline \multirow{2}{*}{\multicolumn{2}{|c|}{ Model }} & \multicolumn{2}{|c|}{$\begin{array}{l}\text { Unstandardized } \\
\text { Coefficients }\end{array}$} & \multirow{2}{*}{$\begin{array}{c}\begin{array}{c}\text { Standardized } \\
\text { Coefficients }\end{array} \\
\text { Beta }\end{array}$} & \multirow[t]{2}{*}{$t$} & \multirow[t]{2}{*}{ Sig. } \\
\hline & & B & $\begin{array}{l}\text { Std. } \\
\text { Error }\end{array}$ & & & \\
\hline & (Constant) & 6,000 & 4,188 & & 1,433 & , 155 \\
\hline & $\begin{array}{l}\text { Emotional } \\
\text { Marketing }\end{array}$ & ,427 & ,067 & 487 & 6,329 & ,000 \\
\hline & $\begin{array}{l}\text { Spiritual } \\
\text { Marketing }\end{array}$ & ,412 & ,084 & 379 & 4,919 & ,000 \\
\hline
\end{tabular}


Sumber: Data Primer, Diolah Tahun 2017

Berdasarkan hasil pengujian hipotesis dengan uji $\mathrm{t}$ (parsial) dapat dihasilkan analisis:

a. Pengaruh emotional marketing $\left(\mathrm{X}_{1}\right)$ terhadap loyalitas nasabah (Y)

Dari hasil penelitian dan analisis data dengan uji t (parsial) dapat diketahui nilai signifikansi untuk pengaruh emotional marketing $\left(\mathrm{X}_{1}\right)$ terhadap loyalitas nasabah (Y) adalah sebesar $0,000<0,05$ dan nilai $\mathrm{t}$ hitung 6,329>t tabel 1,660. Sehingga dapat disimpulkan bahwa terdapat pengaruh positif signifikan emotional marketing $\left(\mathrm{X}_{1}\right)$ terhadap loyalitas nasabah (Y).

Hasil penelitian tersebut sesuai dengan teori dari Robinette yang mengemukakan bahwa emotional marketing adalah usaha yang di lakukan oleh perusahaan untuk menciptakan hubungan yang berkelanjutan dengan para pelanggan, sehingga mereka merasa berharga dan di perhatikan, yang pada akhirnya akan membuat mereka loyal terhadap perusahaan. ${ }^{38}$ Kemudian menurut Robinette konsep pemasaran ini juga mengarah ke strategi berbeda bahkan jarang ditiru dan memberikan keunggulan kompetitif yang kuat. $^{39}$ Dampak dari hubungan secara emosional yang dibangun yaitu meningkatkan loyalitas nasabah terhadap bank syariah. Karena ketika seorang nasabah mempunyai ikatan emosional dan diperlakukan secara lebih maka dia akan memperlakukan sebaliknya kepada bank syariah tersebut, yaitu dengan memberikan loyalitasnya. Hasil dari penelitian ini juga membuktikan bahwa emotional marketing $\left(\mathrm{X}_{1}\right)$ berpengaruh terhadap loyalitas nasabah (Y) sebesar 30,1\%.

38 Osin Tauli dan Marhadi, "Pengaruh Emotion Marketing dan Experiental Marketing terhadap Customer Loyalty Pondok Khas Melayu di Pekanbaru," Jurnal Ekonomi Vol. 20 No. 4 (Desember 2012): 2.

${ }^{39}$ Irene Susilo dan Hatane Semuel, "Analisa Pengaruh Emotional Marketing terhadap Purchase Intention melalui Brand Awareness pada Produk Dove Personal Care di Surabaya," Jurnal Manajemen Pemasaran Vol. 9 No. 1 (April, 2015): 24.
Penelitian ini juga mendukung hasil penelitian terdahulu dari Dessy Wulansari dan Yessy Artanti (2014), Erma Sulistyo Rini (2016), Tias A. Indarwati dan Monika Tiarawati (2015), Riyanti Nur Shobah (2012) yang menghasilkan kesimpulan bahwa konsep pemasaran emotional marketing mempengaruhi loyalitas nasabah.

b. Pengaruh spiritual marketing $\left(\mathrm{X}_{2}\right)$ terhadap loyalitas nasabah (Y)

Dari hasil penelitian dan analisis data dengan uji $\mathrm{t}$ (parsial) dapat diketahui nilai signifikansi untuk pengaruh spiritual marketing $\left(\mathrm{X}_{2}\right)$ terhadap loyalitas nasabah (Y) adalah sebesar $0,000<0,05$ dan nilai $\mathrm{t}$ hitung 4,919>t tabel 1,660. Sehingga dapat disimpulkan bahwa terdapat pengaruh positif signifikan emotional marketing $\left(\mathrm{X}_{1}\right)$ terhadap loyalitas nasabah (Y).

Hasil penelitian tersebut sesuai dengan teori dari Hermawan Kartajaya yang mengemukakan bahwa spiritual marketing adalah bentuk pemasaran yang dijiwai nilainilai spiritual dalam segala proses dan transaksinya hingga ia sampai pada suatu tingkat ketika semua stakeholders utama dalam bisnis (pelanggan, karyawan dan pemegang saham), pemasok, distributor bahkan pesaing sekalipun memperoleh kebahagiaan. $^{40}$ Dampak dari hubungan secara spiritual yang dibangun yaitu meningkatkan loyalitas nasabah terhadap bank syariah. Karena nasabah akan merasa bahwa bank syariah memberikan nilai-nilai spiritual dalam segala prosesnya, dan itu tidak bisa ditemukan pada bank yang beroperasi secara konvensional. Hasil dari penelitian ini juga membuktikan bahwa spiritual marketing $\left(\mathrm{X}_{2}\right)$ berpengaruh terhadap loyalitas nasabah (Y) sebesar $13,9 \%$.

Penelitian ini juga mendukung hasil penelitian terdahulu dari Nur Ayu Rizqia (2013), Langgeng Setyono, Andriani Kusumawati, dan M. Kholid Mawardi (2015) yang menghasilkan kesimpulan bahwa

\footnotetext{
${ }^{40}$ Junaidi Abdillah, "Fikih Pemasaran Menguak Pemikiran Hermawan Kartajaya tentang Syariah Marketing",Jurnal Ijtimaiyya (Pengembangan Masyarakat) Vol. 5 No. 1 (Februari 2012): 34.
} 
konsep pemasaran spiritual marketing mempengaruhi loyalitas nasabah.

\section{Diskusi}

Bank merupakan salah satu lembaga keuangan yang memiliki peran penting dalam perekonomian. Bank merupakan badan usaha yang dapat menghimpun dana dari masyarakat dalam bentuk simpanan dan menyalurkannya dalam bentuk pinjaman kepada pelaku bisnis sehingga kegiatan operasi perusahaan dapat terus berjalan. Bank juga dapat menyalurkan dana yang dihimpun kepada masyarakat dalam rangka meningkatkan taraf hidup nasabahnya.

Sektor perbankan memegang peranan penting dalam peningkatan pertumbuhan ekonomi nasional. Tujuan perbankan adalah sebagai lembaga yang memobilisasi dana untuk mempercepat pembangunan ekonomi. Kegiatan bank yang berupa penghimpunan dan penyaluran dana sangat diperlukan bagi kelancaran kegiatan perekonomian di sektor riil. Kegiatan bank memungkinkan masyarakat untuk melakukan investasi, distribusi, serta konsumsi barang dan jasa.

Dasar utama kegiatan perbankan adalah kepercayaan, baik dalam kegiatan penghimpunan dana maupun penyaluran dana. Masyarakat akan bersedia menyimpan dananya di sebuah bank apabila bank tersebut memiliki reputasi yang baik. Dalam kegiatan ini akan terbangun kepercayaan baik dari pihak penyimpan dana maupun dari pihak bank dan kepercayaan ini akan berlanjut kepada pihak peminjam.

Saat ini industri perbankan merupakan suatu bisnis yang sangat kompetitif. Hal ini mengakibatkan bankbank berloma-lomba untuk menarik nasabah agar menggunakan produk/jasa yang ditawarkan dan menarik nasabah untuk loyal terhadap perusahaannya. Salah satu strategi yang digunakan adalah dengan menerapkan konsep pemasaran emotional marketing dan spiritual marketing.
Dalam menjalankan bisnisnya, membangun loyalitas adalah bukan pilihan lagi dalam dunia perbankan syariah. Terlebih beberapa tahun terakhir ini muncul salah satu trend yaitu kecenderungan nasabah untuk memiliki lebih dari satu rekening tabungan, bahkan juga lebih dari satu rekening kartu kredit yang aktif.

Di Kabupaten Cirebon, yang merupakan kota dengan mayoritas penduduknya muslim, kemunculan perbankan syariah menjadi lebih mudah diterima oleh masyarakatnya. Tidak terkecuali Bank Syariah Mandiri Kantor Cabang Pembantu Siliwangi yang mempunyai lokasi cukup strategis, yaitu dekat dengan masjid utama dan alun-alun kota Cirebon.

Dalam hal loyalitas nasabah di Bank Syariah Mandiri KCP Cirebon Siliwangi, tidak terlepas dari faktor yang mempengaruhinya. Dalam penelitian ini, peneliti mengindikasikan ada dua faktor yang mempengaruhi loyalitas nasaabh terhadap bank syariah yaitu konsep pemasaran emotional marketing dan spiritual marketing.

Dan setelah dilakukannya penelitian pada bulan April 2017 menghasilkan kesimpulan bahwa emotional marketing dan spiritual marketing berpengaruh positif signifikan terhadap loyalitas nasabah tabungan BSM pada Bank Syariah Mandiri KCP Cirebon Siliwangi.

Hal tersebut sesuai dengan kenyataan bahwa Bank Syariah Mandiri menjadi peringkat pertama dalam kategori Bank Syariah untuk title Consumer Choice (pilihan nasabah) dalam Indonesia Best Banking Brand Award 2016 pada tanggal 16 Desember 2016 yang diselenggarakan oleh Warta Ekonomi. Disusul oleh Bank Muamalat pada peringkat dua, dan BNI Syariah pada peringkat ketiga. Dimana dalam menentukan bank yang tepat sebagai kandidat pemenang, tim riset Warta Ekonomi melakukan serangkaian kegiatan riset kuantitatif pada 14-25 November 2016. Kegiatan riset kuantitatif dilakukan menggunakan 
wawancara telepon dan wawancara tatap muka dengan responden yang tersebar di kota-kota besar di Indonesia. Jumlah responden sebanyak 1.800 orang nasabah perbankan yang dipilih secara acak, dengan kriteria responden berusia 20-50 tahun, memiliki produk perbankan, dan pernah merasakan layanan perbankan. ${ }^{41}$

Kemudian penghargaan lain juga didapat oleh Bank Syariah Mandiri pada tanggal 9 Februari 2017 sebagai Bank Syariah predikat Costumer Loyalty Award (penghargaan loyalitas nasabah), yang diselenggarakan oleh Majalah SWA bekerjasama dengan lembaga riset Hachiko.

Hal ini menunjukkan bahwa Bank Syariah Mandiri merupakan Bank Syariah pilihan nasabah dan mempunyai loyalitas nasabah yang baik dibandingkan dengan Bank Syariah lainnya, pada dua tahun terakhir ini.

Namun, tidak menutup kemungkinan Bank Syariah lain akan menyusul Bank Syariah Mandiri, karena persaingan di industri perbankan sangat kompetitif. Untuk itu Bank Syariah Mandiri KCP Cirebon Siliwangi diharapkan mempertahankan dan meningkatkan emotional marketing dan spiritual marketing dari seluruh operasionalnya, karena penelitian menghasilkan kesimpulan bahwa loyalitas nasabah tabungan BSM pada Bank Syariah Mandiri KCP Cirebon Siliwangi 44\% dipengaruhi oleh emotional marketing dan spiritual marketing. Sedangkan sisanya 56\% dipengaruhi oleh faktor lain yang tidak diteliti.

\section{Penutup}

Berdasarkan hasil analisis penelitian, dapat diambil beberapa kesimpulan sebagai berikut:

\footnotetext{
41 Siti Ruqoyah, "Inilah Peraih Indonesia Best Banking Brand Award 2016." Wartaekonomi.co.id, 16 Desember 2016. http://wartaekonomi.co.id/read/2016/12/16/124412 /inilah-peraih-indonesia-best-banking-brandaward-2016.html. diakses 31 Mei 2017 pukul 4:28.
}

Pelaksanaan emotional marketing terhadap loyalitas nasabah tabungan BSM pada Bank Syariah Mandiri KCP Siliwangi Cirebon masuk dalam kategori sangat baik, dengan indikator rata-rata nilai terbesar adalah indikator pegawai bank melayani dengan ramah dan menyenangkan, dan indikator dengan nilai rata-rata terkecil adalah indikator ATM mudah ditemukan dan dijangkau. Pelaksanaan spiritual marketing terhadap loyalitas nasabah tabungan BSM pada Bank Syariah Mandiri KCP Siliwangi Cirebon masuk kategori sangat baik, dengan indikator rata-rata nilai terbesar adalah indikator terdapat fitur layanan kemudahan dalam berzakat, infaq, shadaqah, dan ratarata terkecil adalah indikator pegawai berpenampilan rapi dan sopan. Emotional marketing berpengaruh positif signifikan terhadap loyalitas nasabah tabungan BSM pada Bank Syariah Mandiri KCP Siliwangi Cirebon. Spiritual marketing berpengaruh positif signifikan terhadap loyalitas nasabah tabungan BSM pada Bank Syariah Mandiri KCP Siliwangi Cirebon. Emotional marketing dan spiritual marketing secara simultan (bersama-sama) berpengaruh positif signifikan terhadap loyalitas nasabah tabungan BSM pada Bank Syariah Mandiri KCP Siliwangi Cirebon.

\section{DAFTAR PUSTAKA}

Barori, A, Pengaruh Emotional Marketing, Experiental Marketing, dan Kepuasan Pelanggan terhadap Loyalitas Pelanggan G-Sports Centre Padang. (Skripsi, Fakultas Ekonomi, Universitas Andalas Padang, 2014).

Nurbasari, A, The Impact of Spiritual Marketing on Consumer Behavior in choosing Halal Food (Case study on moslim community in Bandung), Al Hijaz International Refereed Journal for Islamic \& Arabic Studies Issue 10 (Februari 2015): 277. 
Wulansari, D dan Artanti, Y, Pengaruh Pemasaran berdasarkan Pengalaman, Pemasaran Emosional terhadap Loyalitas Pelanggan, Jurnal Ilmu Manajemen Vol. 2 No. 4 (Oktober 2014).

Rini, E.S dan Absah, Y, Analisis Penciptaan Loyalitas melalui Pengaruh Penerapan Strategi Pemasaran Rasional, Emosional, dan Spiritual terhadap Kepuasan Nasabah PT. Bank Sumut Syariah cabang utaman Medan, Jurnal Studi Manajemen dan Bisnis Vol. 2 No. 1 (2015).

Rini, E.S, Pengaruh experential marketing dan emotional marketing terhadap loyalitas pelanggan di STIKOM Bali, Jurnal Ilmiah SISFOTENIKA Vol. 6 No. 2 (Juli 2016).

Siregar, Hafiz E.Pa, Pengaruh Penerapan Strategi Pemasaran Rasional, Emosional, dan Spiritual terhadap Kepuasan dan Loyalitas Nasabah PT. Bank Mandiri Syariah Cabang Medan Ahmad Yani. (Skripsi, Fakultas Ekonomi dan Bisnis, Universitas Sumatera Utara, 2015): 11.

Kartajaya, H, dkk, Banking Competition in 2013 (in the time of regulatory trantition)," MarkPlus Insight Marketing + Social Research Paper (2013): 6-7.

Wahid, H.A, Studi Analisis Pemikiran Muhammad Syakir Sula tentang Model Spiritual Marketing dan Implementasinya dalam Perbankan Syariah (Studi Kasus di Bank Muamalat Indonesia cabang Semarang). (Skripsi, Fakultas Syariah, IAIN Walisongo Semarang, 2011).

Darwish, H, Emotional Marketing. Think Marketing, $10 \quad$ Mei 2013. https://thinkmarketingmagazine.co m/emotional-marketing/. Diakses 13 Maret 2013.

Farida, I, Pengaruh Penerapan Layanan Marketing Syariah dan Kepuasan Pelanggan terhadap Loyalitas
Pelanggan (Rumah Makan Wong Solo Cabang Tebet), (Skripsi, Fakultas Syariah dan Hukum, UIN Syarif Hidayatullah Jakarta, 2011).

Susilo, I dan Semuel, H, Analisa Pengaruh Emotional Marketing terhadap Purchase Intention melalui Brand Awareness pada Produk Dove Personal Care di Surabaya, Jurnal Manajemen Pemasaran Vol. 9 No. 1 (April, 2015): 24.

Abdillah, J, Fikih Pemasaran Menguak Pemikiran Hermawan Kartajaya tentang Syariah Marketing, Jurnal Ijtimaiyya (Pengembangan Masyarakat) Vol. 5 No. 1 (Februari 2012): 34

Setyono, L, Kusumawati, A, dan Mawardi, M.K, Pengaruh spiritual marketing dan citra perusahaan terhadap kepuasan dan loyalitas nasabah (studi pada Bank Muamalat Indonesia Kantor Cabang Malang), Jurnal Administrasi Bisnis Vol. 27 No. 1 (Oktober 2015).

Khuong, M.N and Bich Tram, V.N, The Effects of Emotional Marketing on Consumer Product Perception, Brand Awareness and Purchase Decision (A Study in Ho Chi Minh City, Vietnam), Journal of Economics, Business and Management, Vol. 3, No. 5 (May 2015): 524.

Rizqia, N.A, Pengaruh Faktor Spiritual Marketing terhadap Loyalitas Nasabah (Studi pada Bank Muamalat Indonesia). (Skripsi, Fakultas Syariah dan Ekonomi Islam, IAIN Walisongo Semarang, 2013).

Marhadi, O.T dan Mahardi, Pengaruh Emotion Marketing dan Experiental Marketing terhadap Customer Loyalty Pondok Khas Melayu di Pekanbaru, Jurnal Ekonomi Vol. 20 No. 4 (Desember 2012).

Asytuti, R, Anggraini, M.D, Nasrullah, M., Pengaruh Kepercayaan, Kepuasan terhadap Loyalitas dengan 
Kepemimpinan Pengurus sebagai Variabel Moderating, Jurnal Penelitian Vol. 10 No. 2 (November 2013): 259.

Kusumadewi, R, Pelaksanaan Emotional Marketing melalui The Emotional ES sebagai Pembentuk Loyalitas Pelanggan, Jurnal Al-Amwal Vol. 7 No. 2 (2015): 231.

Nur Shobah, R, Analisis Faktor-faktor yang Mempengaruhi Loyalitas Nasabah. (Skripsi, Fakultas Syariah, IAIN Syekh Nurjati Cirebon, 2012).

Ruqoyah, S, Inilah Peraih Indonesia Best Banking Brand Award 2016. Wartaekonomi.co.id, 16 Desember 2016.

http://wartaekonomi.co.id/read/20 16/12/16/124412/inilah-peraihindonesia-best-banking-brandaward-2016.html. diakses 31 Mei 2017 pukul 4:28.

Sulfiyah, Pengaruh Kualitas Customer Service terhadap Loyalitas Nasabah Pada Bank Muamalat Indonesia Cabang Cirebon. (Skripsi, Fakultas Syariah, IAIN Syekh Nurjati Cirebon, 2012): 12-13.

Indarwati, T.A. dan Tiarawati, M, Strategi pemasaran melalui experience dan emotional marketing terhadap kepuasan dan loyalitas pelanggan di J.Co donuts dan caffee Surabaya, Jurnal Riset Ekonomi dan Manajemen Vol.15 No.1 (Juni 2015).

Sari, W.Y, Analisis Pelaksanaan Pelayanan Transportasi pada Angkutan Trans Metro kota Pekanbaru, (Skripsi, Fakultas Ekonomi dan Ilmu Sosisal, UIN Sultan Syarif Kasim Pekanbaru, 2014): 34 